\title{
STUDI KUAT LENTUR DINDING ANYAMAN BAMBU HITAM (Gigantochloa atroviolacea) PLASTER SEBAGAI ALTERNATIF DINDING BANGUNAN
}

\author{
Dewi Arin Pustakasari, Dr. Gina Bachtiar, MT, Prof. Dr. Amos Neolaka, MPd
}

\section{PENDAHULUAN}

Kebutuhan masyarakat akan rumah selalu meningkat dari tahun ke tahun, maka dari itu kebutuhan bahan bangunan seperti batu bata dan batako sebagai dinding meningkat. Penggunaan tanah persawahan untuk membuat batu bata secara terus menerus, menyebabkan kerusakan lingkungan areal persawahan, maka perlu di cari alternatif bahan lain untuk dinding, salah satunya yakni dinding anyaman bambu hitam plaster.

Dengan memperhatikan kekuatan bambu yang tinggi dan didukung suatu kenyataan bahwa bambu dengan kualitas tinggi dapat diperoleh pada umur 3 sampai 5 tahun, dalam kurun waktu yang relatif singkat, serta dengan mengingat bahwa bambu mudah ditanam dan tidak memerlukan suatu perawatan yang khusus, maka bambu mempunyai peluang besar untuk mengantikan kayu. Melihat dari ketersediaan bahan baku bambu yang melimpah terutama didaerah pedesaan.

Tabel 1. Nilai sifat fisis dan mekanis bambu

\begin{tabular}{|c|c|c|c|c|c|c|}
\hline No. & $\begin{array}{l}\text { Sifat fisis } \\
\text { dan mekanis }\end{array}$ & $\begin{array}{l}\text { Bambu } \\
\text { hitam } \\
\left(\mathrm{kg} / \mathrm{cm}^{2}\right)\end{array}$ & $\begin{array}{l}\text { Bambu } \\
\text { apus } \\
\left(\mathrm{kg} / \mathrm{cm}^{2}\right)\end{array}$ & $\begin{array}{l}\text { Bambu } \\
\text { ater } \\
\left(\mathrm{kg} / \mathrm{cm}^{2}\right)\end{array}$ & $\begin{array}{l}\text { Bambu } \\
\text { bitung } \\
\left(\mathrm{kg} / \mathrm{cm}^{2}\right)\end{array}$ & $\begin{array}{l}\text { Bambu } \\
\text { andong } \\
\left(\mathrm{kg} / \mathrm{cm}^{2}\right)\end{array}$ \\
\hline 1. & $\begin{array}{l}\text { Keteguhan } \\
\text { lentur } \\
\text { maksimum }\end{array}$ & 663 & 546 & 533,05 & 342,47 & 128,31 \\
\hline 2. & $\begin{array}{l}\text { Modulus } \\
\text { elastisitas }\end{array}$ & 99000 & 101000 & 89152,5 & 53173,0 & 23775,0 \\
\hline 3. & $\begin{array}{l}\text { Keteguhan } \\
\text { tekan sejajar } \\
\text { serat }\end{array}$ & 489 & 504 & 584,31 & 416,57 & 293,25 \\
\hline 4. & Berat jenis & 0,83 & 0,69 & 0,71 & 0,68 & 0,55 \\
\hline
\end{tabular}


Dalam penelitian ini dipilih bambu hitam (Gigantochloa atroviolacea) sebagai anyaman karena bambu hitam memiliki daya tahan terhadap serangan bubuk dan memiliki berat jenis yang tinggi. berat jenis dan keteguhan lentur maksimum bambu hitam lebih tinggi dari pada bambu yang lainnya.

Berawal dari pemikiran tersebut diatas, maka penelitian ini akan meneliti mengenai kuat lentur dari dinding anyaman bambu hitam (Gigantochloa atroviolacea) plaster sebagai alternatif dinding bangunan dan nantinya hasil yang diperoleh akan dibandingkan standar kuat lentur papan semen wol kayu (SNI 03-2104-1991).

Berdasarkan latar belakang masalah, maka dapat diidentifikasikan beberapa masalah sebagai berikut: (1) Apa keuntungan dan kelemahan bambu hitam sebagai bahan dinding bangunan?. (2) Bagaimana cara pemanfaatan dinding anyaman bambu hitam plaster sebagai alternatif dinding bangunan?. (3) Berapa nilai kuat lentur dinding anyaman bambu hitam plaster?. (4) Apakah nilai kuat lentur dinding anyaman bambu hitam plaster memenuhi standar kuat lentur papan semen wol kayu (SNI 03-2104-1991)?.

Berdasarkan banyaknya permasalahan yang timbul, maka dalam penelitian ini diberikan batasan masalah yang akan diteliti, yaitu:

1. Dinding bangunan yang diteliti adalah dinding anyaman bambu hitam plaster.

2. Karakteristik yang diuji hanya kuat lentur.

3. Standar yang dipakai dalam pengujian adalah standar papan semen wol kayu (SNI 03-21041991).

4. Plester dinding menggunakan perbandingan $1 \mathrm{Pc}: 5 \mathrm{Ps}$. 
Memperhatikan pembatasan masalah diatas, maka perumusan masalah dapat dirumuskan sebagai berikut: Apakah nilai kuat lentur dinding anyaman bambu hitam plaster memenuhi standar kuat lentur papan semen wol kayu (SNI 03-2104-1991) yaitu sebesar $17 \mathrm{~kg} / \mathrm{cm}^{2} ?$.

\section{Dinding Bambu Plaster}

Konsep konstruksi dinding bambu plaster dikembangkan berdasarkan penelitian rumah bambu plaster peninggalan Belanda yaitu perumahan Jatiroto di Lumajang yang didirikan sekitar tahun 1900 yang mampu bertahan sampai saat ini. Rumah bambu plaster dikembangkan dengan beberapa tujuan, antara lain:

- Alternatif dinding rumah,

- Memanfaatkan potensi bambu,

- Mengurangi resiko kebakaran pada rumah bambu,

- Menambah keawetan konstrusi bambu dengan pemlesteran,

- Alternatif pengganti bata/batako pada dinding tembok.

Kurang lebih 1.000 species bambu dalam 80 genera, sekitar 200 species dari 20 genera ditemukan di Asia Tenggara, sedangkan di Indonesia ditemukan sekitar 60 jenis (K.Widnyana 2008, diacu dalam Dransfield dan Widjaja 1995). Berikut ini adalah beberapa kelebihan bambu jika dipergunakan untuk komponen bangunan, antara lain:

1. Bambu merupakan bahan yang dapat diperbarui (3-5 tahun sudah dapat ditebang).

2. Bambu mempunyai kekuatan tarik yang tinggi (beberapa jenis bambu melampaui kuat tarik baja mutu sedang), ringan, berbentuk pipa beruas sehingga cukup lentur untuk dimanfaatkan sebagai komponen bangunan rangka.

3. Masa konstruksi bambu cukup singkat sehingga biaya konstruksi menjadi lebih murah.

4. Serat bambu yang liat dan elastis sangat baik dalam menahan beban, baik beban tekan/tarik, geser, maupun tekuk. 
5. Bambu merupakan material yang murah karena relatif mudah didapat dan cepat untuk disambung sebagai satu kesatuan struktur yang utuh karena tidak memerlukan tenaga terdidik, cukup dengan peralatan sederhana pada kegiatan pembangunan.

6. Bambu adalah material yang ramah lingkungan, karena sesuai dengan konsep arsitektur hijau yang mudah untuk dikurangi, digunakan kembali atau didaur ulang (reduce, reuse, recycle).

Pemasangan serat dapat dilakukan melalui bentuk anyaman yang diberi adukan beton (Sri Murni Dewi 2005). Mengingat kuat lentur panel bambu plaster pracetak cukup tinggi maka dengan adanya anyaman bambu hitam plaster ini diduga dapat menghasilkan kuat lentur yang tinggi dan memenuhi standar kuat lentur papan semen wol kayu (SNI 03-2104-1991) sebagai alternatif dinding bangunan. Berat jenis dan keteguhan lentur maksimum bambu hitam lebih tinggi dari pada berat jenis bambu apus (Hadjib dan Karnasudirdja,1986) dan (Ginoga, 1977), sehingga bambu yang digunakan untuk penelitian ini adalah bambu hitam. Bambu hitam yang digunakan berasal dari desa Bojong Kulur, Kecamatan Gunung Putri, Kab. Bogor. Bambu yang baik berada pada tengah rumpun dengan spesifikasi fisik yang baik. Setelah bambu ditebang, potong satu ruas bagian bawah dan beberapa ruas atas dengan menggunakan gergaji yang tajam untuk mendapatkan hasil yang baik.

Potong bambu dengan ukuran $200 \mathrm{~cm}$ dan $50 \mathrm{~cm}$ dan belah bambu untuk dianyam. Untuk mendapatkan bilah bambu dengan lebar $2 \mathrm{~cm}$ dipakai alat pembelah bambu (bamboo splitting tool). Belah bambu dengan menggunakan pisau tajam untuk menghilangkan sekat rongga dan bubuk-bubuk yang berada pada ruas bambu bagian dalam, hingga ketebalan kulit yang akan dipakai mencapai $6 \mathrm{~mm}$. Bagian kulit bambu yang dipakai adalah kulit bagian luar saja, karena kandungan pati dan bubuk yang berada dikulit bambu bagian dalam dapat menjadikan bambu tidak awet dan mudah terserang bubuk. Sebaiknya bagian-bagian sisi yang tajam pada bambu disayat agar tidak melukai pada saat menganyam. Anyaman yang digunakan adalah anyaman dua strip dengan jarak antar strip anyaman horizontal sebesar $20 \mathrm{~cm}$, anyaman horisontal dan vertikal dengan posisi kulit bambu bagian luar dan bagian dalam dianyam secara bergantian. Hal ini bertujuan agar anyaman kaku dan kuat dikedua sisinya. Setelah dianyam bambu diberi lapisan vernis dengan tujuan agar pori-pori bambu tertutup sehingga bambu tidak menyerap air spesi dan tidak mengembang, setelah itu bambu dikeringkan. Langkah pertama yang dilakukan dalam pembuatan benda uji adalah pembuatan besi pengaku anyaman. Setelah dilakukan 
pemeriksaan bahan barulah dibuat adukan dengan perbandingan $1 \mathrm{Pc}: 5 \mathrm{Ps}$. Ukuran benda uji yang digunakan adalah panjang $200 \mathrm{~cm}$, lebar $50 \mathrm{~cm}$, dan tebal $5 \mathrm{~cm}$. Semen yang digunakan pada penelitian ini menggunakan semen Holcim.

Pembuatan bambu plester untuk dinding, dilakukan pemelesteran pada 2 sisi yaitu sisi depan dan sisi belakang. Pertama-tama dinding anyaman bambu dikamprot terlebih dulu dengan adukan. 'Pengamprotan' pertama tidak boleh terlalu tebal agar dinding jadi tidak terlalu tebal. Setelah adukan kamprot ini telah cukup kering (setelah didiamkan setengah-satu hari) dapat dilakukan pemlesteran kedua untuk meratakan permukaan dinding. Sebelumnya hasil plesteran awal dibasahi agar tidak banyak menyerap air yang ada pada campuran plesteran baru. Gunakan roskam untuk meratakan/merapikan/menghaluskan permukaan plesteran kedua. Setelah benda uji jadi, lakukan perawatan beton dengan menggunakan karung goni basah selama 28 hari, karena kekuatan tekan beton akan bertambah dengan naiknya umur beton. Secara cepat, kekuatan beton akan linier naiknya sampai umur 28 hari. Setelah itu, kenaikkan kekuatan beton akan kecil. Setelah dilakukan perawatan barulah dilakukan pengujian kuat lentur. Ada dugaan nilai kuat lentur dinding anyaman bambu hitam plaster memenuhi standar kuat lentur papan semen wol kayu (SNI 03-2104-1991), sehingga anyaman bambu plaster dapat digunakan sebagai konstruksi dinding bangunan.

Berdasarkan kerangka berpikir diatas maka dapat dirumuskan hipotesis penelitian yaitu: Nilai kuat lentur dinding anyaman bambu hitam (Gigantochloa atroviolacea) plaster memenuhi standar nilai kuat lentur papan semen wol kayu (SNI 03-2104-1991) yaitu sebesar 17 kg/cm².

\section{METODA}

Tujuan penelitian ini adalah untuk mengetahui apakah nilai kuat lentur dinding anyaman bambu hitam plaster lebih tinggi dari standar kuat lentur papan semen wol kayu (SNI 03-2104-1991).

Tempat penelitian dilakukan di laboratorium bahan non logam Balai Penelitian Bahan dan Barang Teknik Dinas Perindustrian DKI, yang beralamat di jalan Letjen. Suprapto Cempaka Putih, Jakarta Pusat. Waktu penelitian dimulai dari bulan Juli 2010 sampai dengan September 2010. 
Metode penelitian yang digunakan adalah metode penelitian eksperimen di laboratorium bahan non logam Balai Penelitian Bahan dan Barang Teknik Dinas Perindustrian DKI.

Populasi pada penelitian adalah dinding anyaman bambu hitam plaster.

Sampel yang digunakan sebanyak 7 buah benda uji berbentuk pelat dengan panjang $200 \mathrm{~cm}$, lebar $50 \mathrm{~cm}$, dan tebal $5 \mathrm{~cm}$ berumur 28 hari.

Instrument penelitian yang digunakan pada penelitian ini terdiri dari: bahan yang digunakan adalah semen portland komposit (PCC), pasir, anyaman bambu menggunakan bambu hitam, kawat beton, karung goni, dan air. Alat yang digunakan adalah mesin tes kekuatan lentur, mesin molen, seperangkat alat timbang dan neraca, seperangkat alat untuk uji analisis gradasi agregat, gelas ukur, dan blangko pengamatan.

Pada penelitian ini terdapat dua variabel, yaitu :

1. Variabel bebas yaitu dinding anyaman bambu hitam plaster.

2. Variabel terikat yaitu nilai kuat lentur

Dalam penelitian ini terdapat tahapan-tahapan pelaksanaan pengujian, yaitu :

\section{Tahap persiapan}

Tahap persiapan merupakan tahap awal dan penting dalam penelitian, karena pada tahap inilah bahan dan alat dipersiapkan sehingga persiapan harus matang sebelum dilakukan pengujian bahan. Persiapan bahan dimulai dari memotong bambu sesuai ukuran dengan menggunakan gergaji yang tajam untuk mendapatkan hasil potongan yang baik. Setelah dipotong, kemudian bambu dibilah dengan lebar $2 \mathrm{~cm}$ dengan menggunakan alat pembelah bambu (bamboo splitting tool). Bersihkan bubuk bambu yang terdapat pada ruas bambu dan belah bambu dengan menggunakan pisau tajam hingga ketebalan kulit bambu mencapai $6 \mathrm{~mm}$.

Setelah proses memotong dan membelah selesai, kemudian bambu dianyam menjadi anyaman dua strip dengan jarak antar strip horizontal sebesar $20 \mathrm{~cm}$, arah horisontal dan arah vertikal dengan posisi kulit bambu bagian luar dan bambu bagian dalam dianyam secara bergantian agar anyaman menjadi kaku dan kuat. Kemudian anyaman bambu diberi vernis agar pori-pori bambu 
tertutup sehingga bambu tidak menyerap air spesi dan tidak mengembang, setelah itu bambu dikeringkan. Untuk campuran adukan dipakai perbandingan

$1 \mathrm{PC}: 5$ pasir.

Karena bambu hitam cenderung awet dan kandungan bubuk di dalam relatif rendah serta adanya keterbatasan waktu dan tempat, maka pada penelitian ini tidak dilakukan proses pengawetan bambu terlebih dahulu, selain itu bambu yang dipakai pada penelitian ini telah mengalami proses pengeringan secara alami selama 2 minggu ditempat yang tidak terkena matahari langsung.

\section{Tahap pemeriksaan bahan}

Tahap pemeriksaan bahan yang dimaksud adalah untuk mengetahui sifat dari bahan-bahan yang digunakan dalam pembuatan benda uji dalam penelitian diantaranya adalah:

1. Pemeriksaan kadar lumpur agregat halus (SNI 03-4142-1996).

2. Pemeriksaan kadar zat organik dalam agregat halus (SNI 03-2816-1992).

3. Pemeriksaan gradasi agregat halus (SNI 03-6822-2002).

4. Pemeriksaan berat jenis dan penyerapan agregat halus (SNI 03-1970-1990).

5. Kadar air bambu.

\section{Pembuatan benda uji}

Setelah dilakukan pengujian terhadap bahan maka dibuatlah benda uji dengan terlebih dahulu menentukan ukuran benda uji yang mengacu pada SNI 03-2104-1991, mengenai papan semen wol kayu. Papan semen wol kayu adalah bahan bangunan yang terbuat dari wol kayu, semen Portland, air dan bahan tambah kimia, dibentuk menjadi suatu papan kaku yang berongga.

Penggunaan SNI tersebut digunakan sebagai acuan dalam penelitian ini dikarenakan belum adanya standar mengenai bambu dan bambu plester. Adanya kemiripan perlakuan pada benda uji antara papan semen wol kayu dan anyaman bambu hitam plaster yaitu memasukkan bahan organik pada campurannya sehingga perlakuan benda uji pada penelitian ini mengikuti standar tersebut. Jadi, ukuran benda uji yang digunakan pada anyaman bambu hitam plaster adalah: panjang $200 \mathrm{~cm}$, lebar $50 \mathrm{~cm}$, dan tebal $5 \mathrm{~cm}$.

Langkah pertama yang dilakukan dalam pembuatan benda uji adalah pembuatan anyaman dan besi pengaku anyaman. Setelah itu membuat adukan dengan perbandingan 1 PC : 5 Pasir. 
Semen yang digunakan pada penelitian ini menggunakan semen Holcim. Pembuatan bambu plester untuk dinding, dilakukan pemelesteran pada 2 sisi yaitu pada sisi depan dan belakang. Pertama-tama dinding anyaman bambu dikamprot terlebih dulu dengan adukan. 'Pengamprotan' pertama tidak boleh terlalu tebal agar dinding jadi tidak terlalu tebal. Setelah adukan kamprot ini telah cukup kering (setelah didiamkan setengah-satu hari) dapat dilakukan pemlesteran kedua untuk meratakan permukaan dinding. Sebelumnya hasil plesteran awal dibasahi agar tidak banyak menyerap air yang ada pada campuran plesteran baru. Gunakan roskam untuk meratakan/merapikan/menghaluskan permukaan plesteran kedua.

\section{Pengujian kuat lentur}

Pengujian kuat lentur bertujuan untuk mengetahui kekuatan maksimal bambu plester pracetak dalam memikul beban dan sangat tergantung pada bahan baku yang digunakan dan besarnya beban maksimal yang dapat dipikul suatu lembaran. Pengujian kuat lentur perlu dilakukan karena dinding menerima beban horisontal seperti beban angin, serta beban vertikal seperti beban sendiri.

Cara pengujian kuat lentur diambil dari setiap benda uji berumur 28 hari. Sebelum dilakukan pengujian, sampel terlebih dahulu diukur dan ditimbang beratnya menggunakan alat ukur dan timbangan yang telah ditentukan. Setelah itu, sampel diletakkan di atas dua pisau lentur penumpu yang jaraknya $1320 \mathrm{~mm}$. beban diberikan melalui pisau lentur pada tengah - tengah kedua penumpu (jaraknya $660 \mathrm{~mm}$ dari masing - masing pisau penumpu), dengan kecepatan beban secara tetap sebesar $2 \mathrm{~kg} /$ sekon sampai patah.

Rumus kuat lentur bambu plaster dihitung menggunakan persamaan sebagai berikut : (SNI 032104-1991)

Kuat Lentur $\quad=\frac{3 P l}{2 b h^{2}} \mathbf{k g} / \mathrm{cm}^{2}$

Keterangan:

$\mathrm{P}=\operatorname{beban}$ patah $(\mathrm{kg}) \quad \mathrm{b}=$ lebar benda uji $(\mathrm{cm})$

$\mathrm{I}=$ jarak tumpuan $(\mathrm{cm}) \mathrm{h}=$ tebal rata-rata bidang pecah $(\mathrm{cm})$

Kuat lentur dilaporkan dari tiap-tiap benda uji, dan dihitung rata-ratanya. Langkah-langkah penelitian di laboratoium dilakukan menurut diagram alir di bawah ini :

\section{Teknik Analisis Data}


Sebelum dilakukan pengujian hipotesis, data terlebih dahulu diuji normalitas. Uji normalitas dilakukan untuk menguji apakah sampel yang diselidiki berasal dari populasi yang berdistribusi normal. Dalam hal ini uji normalitas yang digunakan adalah uji liliefors. Uji homogenitas tidak perlu dilakukan karena sampel hanya berasal dari satu populasi, jadi sampel yang diuji sudah tentu homogen.

Setelah memenuhi keduanya, maka dilakukan pengujian hipotesis dengan menggunakan uji t, rata-rata satu pihak.

\section{Hipotesis Statistik}

Hipotesis statistik yang digunakan dalam penelitian ini dapat dirumuskan sebagai berikut:

1. $H_{0}: \mu_{A}=\mu_{B}$

2. $H_{1}: \mu_{A}>\mu_{B}$

Keterangan:

1. $\mu_{A}=$ kuat lentur hasil pengujian laboratorium.

2. $\mu_{B}=$ standar nilai kuat lentur papan semen wol kayu $=17 \mathrm{~kg} / \mathrm{cm}^{2}$

(SNI 03-2104-1991)

\section{HASIL DAN PEMBAHASAN}

\section{Deskripsi Data}

\section{Data Pendahuluan / Data Mentah}

Pengujian awal pada penelitian ini dilakukan untuk menentukan sifat fisis agregat halus pasir seperti: pengujian kadar lumpur, kandungan zat organik, uji gradasi butiran, uji berat jenis dan penyerapan air pada agregat yang di gunakan sebagai bahan pembuat beton. Untuk bahan bambu hanya dilakukan pengujian kadar air bambu. Hasil pengujian awal bahan dapat dilihat pada Tabel 1.

\begin{tabular}{|l|l|c|c|c|c|}
\hline No. Lampiran & Pengujian Bahan & $\begin{array}{c}\text { Standar Yang } \\
\text { Digunakan }\end{array}$ & Hasil Pengujian & Syarat SNI & Ket \\
\hline
\end{tabular}




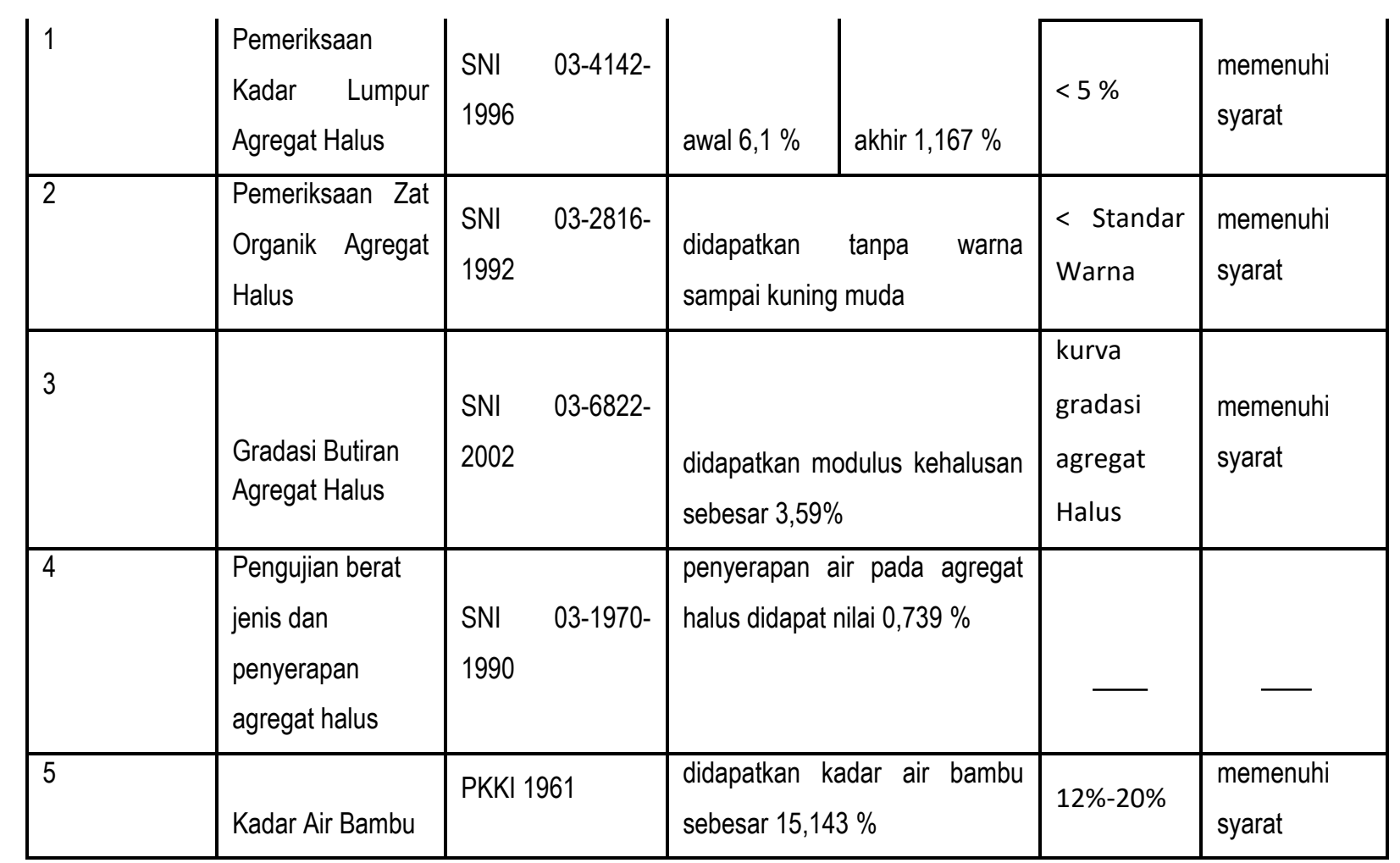

Tabel 1 Hasil pengujian bahan

Pengujian anyaman bambu hitam plaster dilakukan pada saat benda uji berumur 28 hari. Sebelum dilakukan pengujian kuat lentur terlebih dahulu benda uji diukur panjang, lebar, tebal, dan ditimbang beratnya satu persatu. Pengujian lentur anyaman bambu hitam plaster dilakukan dengan meletakkan benda uji di atas dua pisau lentur penumpu yang jaraknya $1320 \mathrm{~mm}$. Beban diberikan melalui pisau lentur pada tengah-tengah kedua penumpu (jaraknya $660 \mathrm{~mm}$ dari masing-masing pisau penumpu), dengan kecepatan beban secara tetap sebesar $2 \mathrm{~kg}$ per sekon sampai patah dan jarum penunjuk beban lentur tidak bergerak lagi. Hasil data awal pengujian kuat lentur anyaman bambu hitam plaster dapat dilihat pada Tabel 2 di bawah ini.

Tabel 2 Data awal hasil pengujian anyaman bambu hitam plaster. 


\begin{tabular}{|c|c|c|c|c|c|c|}
\hline \multirow{2}{*}{ No. } & \multirow{2}{*}{$\begin{array}{c}\text { Kode } \\
\text { Benda Uji }\end{array}$} & \multirow{2}{*}{$\begin{array}{c}\text { Berat } \\
(\mathrm{kg})\end{array}$} & \multicolumn{3}{|c|}{ Dimensi Bambu Plaster } & \multirow{2}{*}{$\begin{array}{c}\text { Beban } \\
\text { Lentur }(\mathrm{kg})\end{array}$} \\
\hline & & & Panjang (cm) & Lebar $(\mathrm{cm})$ & Tebal (cm) & \\
\hline 1 & S-1 & 105,3 & 200 & 50 & 5,8 & 572 \\
\hline 2 & S-2 & 106,2 & 200,2 & 50,5 & $\overline{5,5}$ & 508 \\
\hline 3 & S-3 & 108,15 & 200,4 & 50 & 5,4 & 560 \\
\hline 4 & S-4 & 98,2 & 200 & 50 & 5,5 & 419 \\
\hline 5 & S-5 & 110,2 & 200,2 & 50 & 5,6 & 562 \\
\hline 6 & S-6 & 95,8 & 200 & 50 & $\overline{5,4}$ & 340 \\
\hline 7 & S-7 & 99,8 & 200,5 & 50 & 5,7 & 540 \\
\hline \multicolumn{2}{|c|}{ Rata-Rata } & 103,379 & 200,186 & 50 & 5,6 & 500,143 \\
\hline
\end{tabular}

\subsubsection{Pengolahan Data Hasil Pengujian Kuat Lentur}

Tabel 3 Pengolahan hasil penelitian kuat lentur anyaman bambu hitam plaster

\begin{tabular}{|c|c|c|c|c|c|c|c|c|}
\hline No. & $\begin{array}{c}\text { Kode } \\
\text { Benda } \\
\text { Uji }\end{array}$ & $\begin{array}{c}\text { Beban } \\
\text { Lentur } \\
P \\
(\mathrm{~kg})\end{array}$ & $\begin{array}{c}\text { Jarak } \\
\text { Tumpuan } \\
\text { I } \\
\text { (cm) }\end{array}$ & $\begin{array}{c}\text { Lebar } \\
\text { Benda } \\
\text { Uji } \\
\text { b } \\
(\mathrm{cm})\end{array}$ & $\begin{array}{c}\text { Tebal } \\
\mathrm{h} \\
\\
\text { (cm) }\end{array}$ & $\begin{array}{c}\text { Kuat Lentur } \\
\mu_{B}=\frac{3 P l}{2 b h^{2}} \\
\left(\mathrm{~kg} / \mathrm{cm}^{2}\right)\end{array}$ & $\begin{array}{l}\text { Kuat } \\
\text { Lentur } \\
\text { Rata- } \\
\text { Rata }\end{array}$ & $\begin{array}{l}\text { Hipotesis } \\
\text { Statistik }\end{array}$ \\
\hline 1 & S-1 & 572 & 132 & 50 & 5,8 & 67,33 & \multirow{7}{*}{$\begin{array}{l}63,86 \\
\mathrm{~kg} / \mathrm{cm}^{2}\end{array}$} & \multirow{7}{*}{$\begin{array}{l}\mu_{B}>17 \\
\mathrm{~kg} / \mathrm{cm}^{2}\end{array}$} \\
\hline 2 & S-2 & 508 & 132 & 50,5 & 5,5 & 65,84 & & \\
\hline 3 & S-3 & 560 & 132 & 50 & 5,4 & 76,05 & & \\
\hline 4 & $\overline{S-4}$ & 419 & 132 & 50 & 5,5 & 54,85 & & \\
\hline 5 & S-5 & 562 & 132 & 50 & 5,6 & 70,97 & & \\
\hline 6 & S-6 & 340 & 132 & 50 & 5,4 & 46,17 & & \\
\hline 7 & S-7 & 540 & 132 & 50 & 5,7 & 65,82 & & \\
\hline
\end{tabular}

Setelah didapatkan data awal pada Tabel 4.2 Selanjutnya dilakukan penghitungan kuat lentur dengan menggunakan data 7 buah benda uji. Perhitungan kuat lentur anyaman bambu hitam plaster dapat dilihat pada Tabel 3 
Dari hasil pengolahan data hasil penelitian kuat lentur anyaman bambu hitam plaster pada Tabel 3 diatas didapatkan kuat lentur rata-rata sebesar $63,86 \mathrm{~kg} / \mathrm{cm}^{2}$.

Dari hasil pengujian normalitas dengan pengujian liliefors, diperoleh data terbesar $L_{\theta}=0,38$ dengan $n$ sampel $=7$, taraf $\alpha=0.05$, dari daftar nilai kritis untuk uji Liliefors didapat $L$ tabel $=$ 0,300 . ternyata $L$ hitung $<L$ table, maka dapat disimpulkan bahwa data tersebut berdistribusi normal. Berdasarkan perhitungan pengujian hipotesis menguji rata-rata uji satu pihak (uji t) diperoleh $\mathrm{t}$ hitung $=88,42$ dan $\mathrm{t}$ tabel $=1,90$ maka hipotesis $t_{\text {hitung }}>t_{\text {tabel }}$ terpenuhi artinya Ho ditolak dan sekaligus alternatif $\left(\mathrm{H}_{1}\right)$ diterima. Dengan demikian nilai kuat lentur bambu plaster lebih tinggi dari standar nilai kuat lentur papan semen wol kayu SNI 03-2104-1991.

\section{Pembahasan Hasil Penelitian}

Dari hasil penelitian kuat lentur anyaman bambu hitam plaster pada Tabel 4.4 dapat diperlihatkan pada grafik dibawah ini.

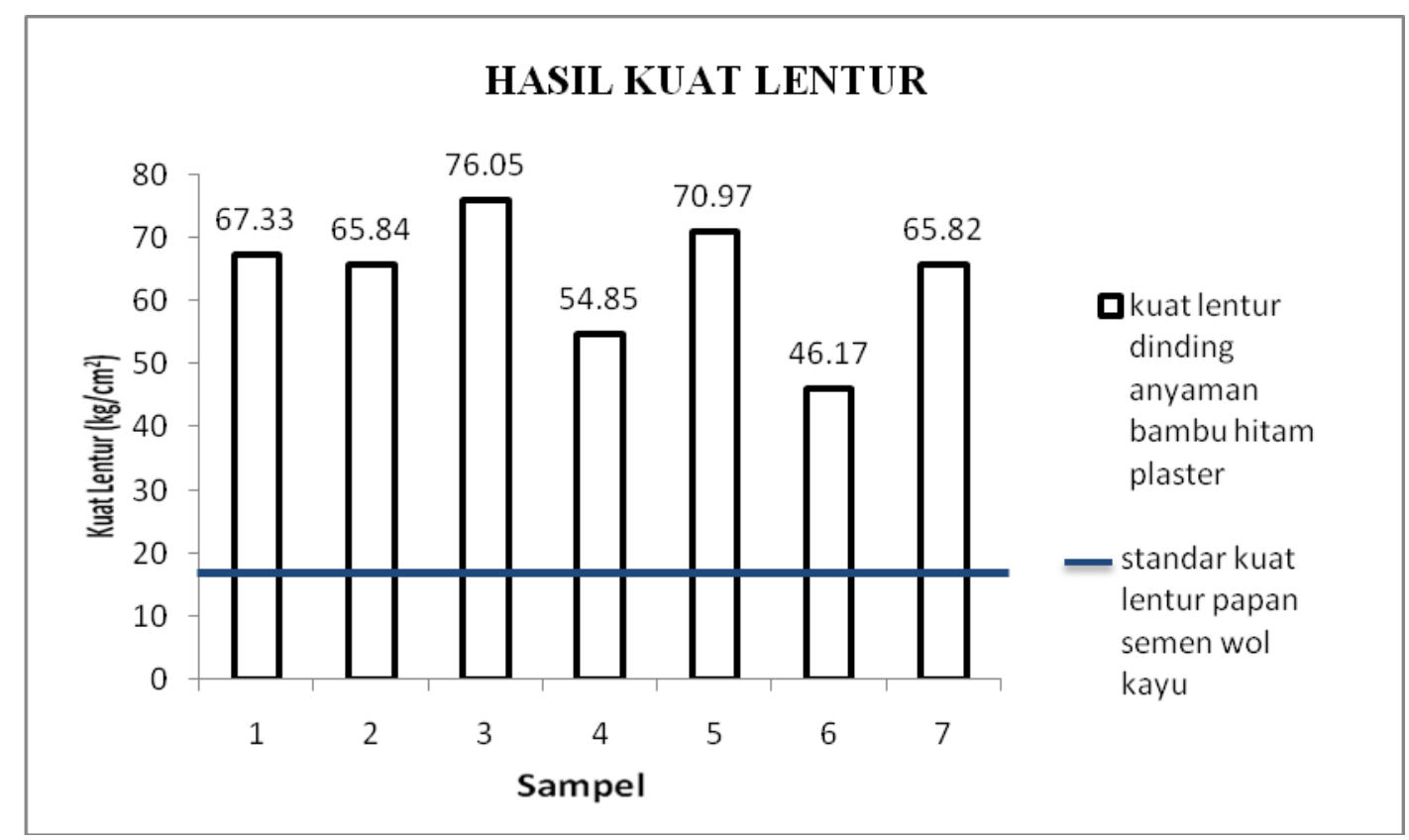

Gambar 4.1 Grafik Variasi Kekuatan Lentur Anyaman Bambu Hitam Plaster

Berdasarkan data hasil pengolahan pada Tabel 4.3 hasil penelitian yang diperoleh adalah kuat lentur dinding anyaman bambu hitam plaster sebesar $63,86 \mathrm{~kg} / \mathrm{cm}^{2}(6,26 \mathrm{MPa})$ memenuhi standar nilai kuat lentur papan semen wol kayu yaitu sebesar 17 kg/cm² (SNI 03-2104-1991), sehingga dapat dijadikan alternatif dinding bangunan yang baik. Dari hasil pengujian kuat lentur 
yang baik, dapat disimpulkan bahwa dinding anyaman bambu hitam plaster dapat digunakan sebagai dinding interior maupun eksterior bangunan.

\section{Keterbatasan Penelitian}

Dalam penelitian ini peneliti mengakui bahwa masih ada banyak keterbatasan yang dapat menyebabkan kekeliruan yang disebabkan oleh beberapa hal, antara lain:

1. Penelitian ini hanya menguji kuat lentur dinding anyaman bambu hitam plaster.

2. Masih sedikitnya literatur mengenai bambu plaster serta belum adanya standar kekuatan lentur mengenai bambu plaster di Indonesia yang dapat dijadikan acuan.

3. Belum adanya standar mengenai dinding anyaman bambu plaster sehingga menggunakan standar yang mendekati yaitu papan semen wol kayu (SNI 03-2104-1991).

4. Jumlah sampel yang digunakan hanya 7 buah benda uji.

\section{KESIMPULAN}

Berdasarkan hasil penelitian kuat lentur dinding anyaman bambu hitam plaster dapat disimpulkan sebagai berikut:

1. Didapatkan nilai kuat lentur yang cukup tinggi antara $46,17-76,05 \mathrm{~kg} / \mathrm{cm}^{2}$, sehingga dapat digunakan sebagai dinding bangunan baik untuk interior maupun eksterior.

2. Dibandingkan dengan standar nilai kuat lentur papan semen wol kayu yaitu sebesar 17 $\mathrm{kg} / \mathrm{cm}^{2}$ (SNI 03-2104-1991) dan panel beton ringan berserat (SNI 03-3122-1992) dengan kuat lentur min. 16,62 kg/ $/ \mathrm{cm}^{2}$, kuat lentur anyaman bambu hitam plaster lebih tinggi.

3. Dari standar yang dipersyaratkan pada SNI 03-6820-2002 mengenai spesifikasi agregat halus untuk pekerjaan adukan dan plasteran dengan bahan dasar semen. Pasir yang digunakan dalam penelitian memenuhi standar gradasi yang disyaratkan, dan hasil kandungan lumpur pada pasir memenuhi standar SNI 03-4142-1996 yaitu kurang dari 5\% dan didapatkan hasil penelitian sebesar $1,167 \%$.

4. Dari segi pengerjaannya pembuatan dinding anyaman bambu hitam plaster tidak ada kesulitan, hanya perlu melatih keterampilan. 
